\title{
NEW USES OF INSTAGRAM IN DESIGN HISTORY EDUCATION
}

\author{
Bryan HOWELL, Joshua SIEBERT and Michaela HILL \\ Brigham Young University
}

\begin{abstract}
Last year we initiated the use of Instagram into our design history course at an introductory level. This year we explored further integration of Instagram as an academic tool. This study included twenty-two undergraduate participants who prototyped five new classroom uses of Instagram: posting full student presentations, utilising Instagram desktop view as the primary in-class presentation tool, employing templates enabling a cohesive visual identity and a simple search process, and methods to enhance student comments. We surveyed course participants mid-semester asking students about their personal Instagram use, the value and purpose they felt Instagram had in the course, and on the usefulness of the presentation templates. We learned that while the majority of students use Instagram in their daily life, few of them make comments on personal or course posts and will only do so for credit. We also learned that while students might not enjoy using Instagram in the course, they find it of value and highly meaningful. Finally, the students prefer using formatted templates over an open style like PowerPoint to build their presentations in. These templates enabled the students to post their full presentations and created a visual cohesiveness for the account while providing a rudimentary search process for individual posts. We will continue using Instagram in future courses with the exception of requiring comments. We believe that students will reference their class posts in years to come, and as they do, it will re-enforce their design knowledge and provide evidence of their personal growth.
\end{abstract}

Keywords: Social media, alassroom archive, industrial design history, Instagram student presentations, Instagram search

\section{INTRODUCTION}

Instagram is currently the fastest growing social networking site in the world due largely to its increasing popularity in social and professional realms. Social media, and by extension the internet as a whole, is central to presentation and discourse in the design marketplace and students are constantly exploring and interacting with design online. This being the case, we chose to explore how this familiar tool might be fully utilised to help students better process the content of their history of design course.

As design students generally utilise this tool in their daily or weekly media interactions, its potential lies fundamentally in its ability to move class content to a platform that is both referenced often and is familiar to students [1]. Though Instagram is predominately used for social purposes, the use of this tool in the classroom has the capacity to open doors that current curriculums cannot. Students can have an effective space to share class content and information on their own time and potentially be able to extend their classroom experience, thus creating and supporting academic conversations outside of the class [2]. It has further been hypothesised that using Instagram in education yields the opportunity for students to connect with professionals [3], and even improves the quality of student work due to the public nature of Instagram content [4].

Last year we introduced Instagram into our design history course by using it to encourage conversations about designers outside of class and provide a summary post of student presentations made in the classroom [5]. We wrote about that experience and presented the findings at E\&PDE'18. After both the class and the conference, students and design educators were curious to understand and explore how else Instagram might be used in design education. Consequently, this year we explored how to utilise the platform beyond posting simple summaries. This paper covers the various experiments we prototyped as we searched for the "best practices" in the use of Instagram as a useful, useable and desirable educational tool within our design history course. 
In the previous year, there were some obvious shortcomings using Instagram in our design course. First, students spent considerable time creating a 15-20 minute classroom presentation about a designer and then would post a 1-3 page summary for that work. If a student was not present for the lecture, they missed out on the content and had no meaningful way to access that information at a later date. Second, postings on Instagram are not searchable, making re-evaluation or future referencing difficult. Third, the summaries that were posted had no visual cohesion, each post looked and felt different. A review of the images posted that year show few words, an abundance of designer portraits who you might or might not recognise and a plethora of graphical styles. Finally, student comments were required for each post. During the first month of class students happily participated in designerly discussions under the comments function. However, by the end of the course, they were exhausted and complaining about the required participation, which resulted in poor quality comments.

For this year's course we addressed each of the previous weaknesses. We prototyped:

1. How each student might post their full classroom presentation to the Instagram feed

2. Whether or not the Instagram platform could be used as an in-class presentation tool

3. Creating a cohesive visual identity for the student posts

4. Designing a rudimentary search process to help find individual designers that students posted

5. How to increase frequency and depth of posted student comments on presentations

We believed that if we utilise the Instagram platform in a more integrated and thoughtful way, we could increase the educational experience for course participants and any public that may follow the account.

\section{METHODOLIGIES}

Participants in this exploration included 22 students from Brigham Young University (BYU). 17 of these students came from the Industrial Design programme, 3 from Graphic Design, 1 from Mechanical Engineering and 1 from Social Science.

For the course, students were assigned historical or contemporary designers whose work they explored and evaluated to inform a 15-20 minute class presentation containing historical facts about their life and training, images of their work, video if available, and contemporary examples of designs that could have been influenced by that designer. Typically, three students presented every class period with each student presenting on two designers or topics, resulting in a semester total of roughly 130 designers covered. The structure for the presentation content follows the laddering outlined in Bloom's revised taxonomy [6] and as described in our previous paper [5]. At the conclusion of their presentations, students were expected to lead a 5-10 minute class discussion on the outcomes derived from their research by asking questions, such as: how do we value this work and what elements from this work can we apply to our own work?

\subsection{Posting the Complete Presentation}

In the previous course, students posted a verbal summary and 2-3 slideshow pages of their designer's key works. This had two negative consequences, first it required the student to summarise and convert portions of their in-class presentation to an Instagram format, and second, only a portion of the full presentation was posted. Consequently, this year students were required to build their presentations around the 10 page slideshow limit as set by Instagram and discuss only one designer per individual post. Thus, each student would post their complete in-class presentation. We continued using the same shared Instagram account (@byudesignhistory) as last year and the account is open to the public.

\subsection{Using Instagram Desktop as an In-Class Presentation Tool}

In previous years, students presented using PowerPoint style slides in the classroom. This year, we explored using the Instagram desktop platform as the in-class presentation tool. The desktop Instagram layout provides an arrow on each side of the images that allows the students to click through the slideshow, forward or backwards, similar to the keyboard arrow control feature in PowerPoint. We believed that the slideshow feature in Instagram would visually perform similar to PowerPoint, but with a 10 slide limit. With the requirement to post presentations to Instagram, using Instagram as the primary presentation tool would save the student time by eliminating the need to convert their PowerPoint presentation to the Instagram format. 


\subsection{Presentation Templates}

To build a cohesive visual identity for the posts, we first created an Adobe InDesign template with a vertical orientation (4:5), thus maximising space within Instagram when viewed on a mobile device. Within a week of use, we altered the template to a square format (1:1) to avoid the unintended cropping of posted content, see the images on the left side versus the right side of Fig 1.
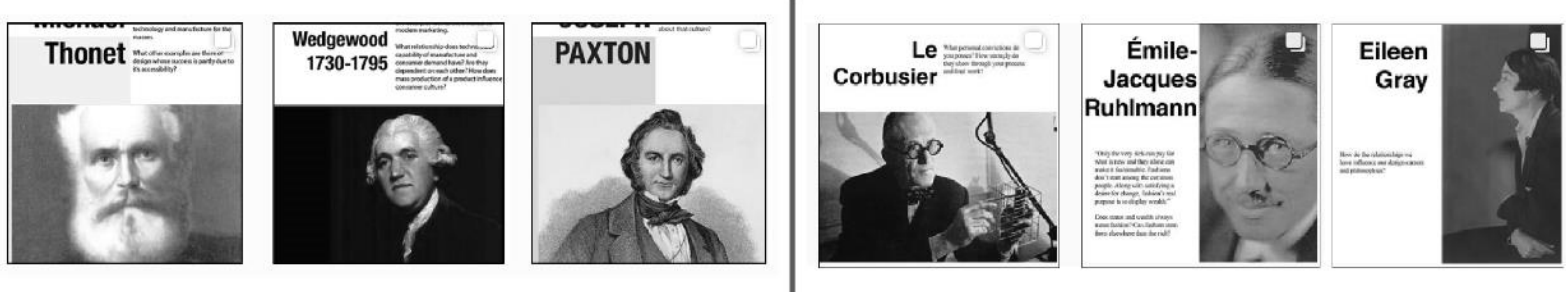

Figure 1. The vertical template on the left versus the square template on the right

The template is divided into four square parts giving students flexibility to create and fill the square sections with either text, images, or graphics, see Fig 2 . Thus, a common visual identity was established while still allowing the students some freedom to manipulate the pages to their individual needs.

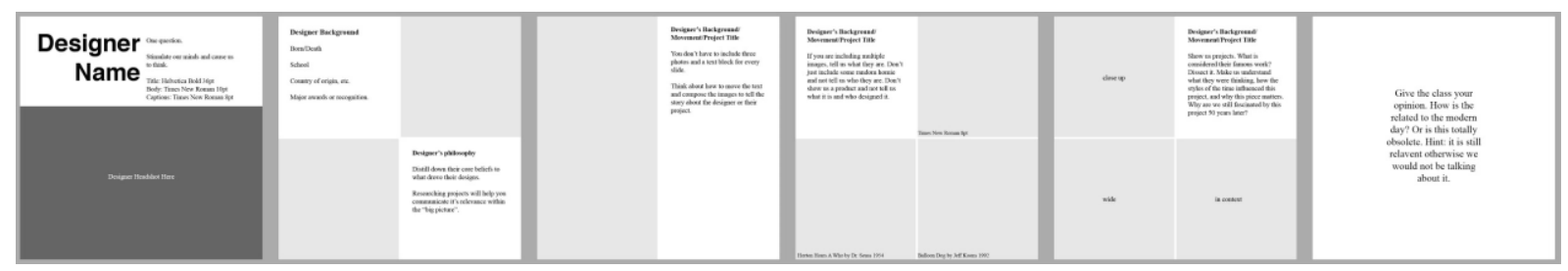

Figure 2. Showing the required title slide on the left and five template variations

\subsection{Search Function}

Previous course posts typically highlighted an image of the designers on the first page. While this was visually appealing, viewers had to know the designer well enough to identify them by face. There is currently no search function on Instagram, so we designed our own rudimentary search function. To this end we set a guideline that the first slide would display the designers name and would be in a significantly larger font as shown in the first template in Fig 2. This would allow viewers to scroll through the feed and quickly locate a designer by written name rather than by face identification.

\subsection{Student Comments}

In the previous course, students were required to make a comment of some sort on each post. The hope was that students would increase their conversations outside of the classroom about classroom topics using a platform they were already using on a daily or weekly basis. This was met with some pushback from the students by the end of the semester. They were tired of the forced commenting for credit, and, by the end of the course, the quality of the comments had dropped significantly. This year we discussed grading the quality of the post rather than simply whether or not they posted. However, we felt that while this might increase the thoughtfulness of a post, it would not overcome the feeling of forcing a conversation. Therefore, this year we tried a number of different comment guidelines to see which proposal would be preferred. The first proposal was that comments were not required, but minimal extracredit points were given for participation. A second proposal required all students to comment for points over a two-week period. The final proposal eliminated all posting expectations with no points given even if a student commented. We made a point of occasionally discussing comments in class and the instructor would also participate in posting comments along with the students. Comments were assessed at the end of the day on each Friday.

\subsection{Mid-Course Survey}

To measure our progress, we administered a mid-course survey to gather insights about student interactions with Instagram and the presentation template. This 10 question survey asked students how often per day or week they: 1; accessed their Instagram accounts in general, 2; posted comments on Instagram outside of the course posts and 3; look at the design history course posts but do not comment. 
For questions four through seven, they were asked to rate on a scale of 1-10, 4; the value of using Instagram in the course, 5; their purpose for commenting on the course Instagram content, either for extra credit or educational conversation and 6 and 7; how enjoyable and how meaningful was using Instagram in this course. We then asked if 8; using the provided presentation templates were helpful or a hindrance and 9; whether or not they would rather use the PDF templates or PowerPoint as a presentation tool. Finally, they were asked an open response question 10; how they might improve the use of Instagram in the course.

\subsection{Abandoned Explorations}

We attempted a few other Instagram use explorations, but quickly abandoned them. For one, we requested that students post their presentations 24 hours before the class started, enabling all the students to preview the content and perhaps post comments or questions about the designer. This goal was rarely achieved, and we dropped it. We also recorded and posted two live student lectures and discussions, using the Instagram Live function. This feature streams a video for up to an hour. While we liked the prospect that the entirety of a course presentation and discussion could be available online for review, it was unwieldy to record using a student's phone and few, if any, people viewed the lectures. We also explored using Instagram Stories. The class assistant would post an image, insert a caption identifying the designer or style and encourage a free response discussion between students and viewers. This effort demonstrated little if any response and was also terminated.

\section{RESULTS}

Student ratings for this year's overall course received a 4.3 out of 5.0 with a $95 \%$ response rate. This score was lower than the historical average of 4.6 out of 5 . While the majority of responses were positive, the poorest scores showed a weakness in course organisation. This is understandable as presentation content and methods, template use, and comment expectations abruptly changed a number of times during the semester. However, these ongoing changes were necessary to understand the best uses of Instagram as an educational tool.

\subsection{Posting the Complete Presentation}

Students had no noticeable issues posting their complete presentations. The flexibility of the templates allowed for numerous images and text blocks to be used, and the 10 page slideshow limit did not receive any complaints. In fact, this limit might have provided an unforeseen benefit by limiting the amount of spaced that could be used. Some students in the past made 30-40 page slide decks which were not as concise in message as they could have been.

\subsection{Instagram as a Presentation Tool}

We found that adopting the Instagram desktop platform as the main presentation tool required some retraining of the student's expectations and experiences. First, the mobile Instagram experience is about quickly digestible images that are easily flipped through. Migrating its use to a paced presentation tool is contrary to the student's natural experience associated with Instagram.

Second, the format of Instagram is not optimised for projected viewing. The Instagram desktop format has a horizontal orientation, while the mobile format is vertical. The horizontal format presents the image to the left side of the comments section and those two elements are framed within the larger desktop space which has a significant circumventing border. Consequently, a single slide page utilises a small portion of the available white space provided on a projection screen and thus images and text are significantly smaller when compared to a PowerPoint type slide and proved difficult for the audience to view and read.

Third, students naturally have some level of presentation anxiety. As a result, they often clicked the wrong advancing arrow when they desired to move to their next slide. The Instagram desktop format provides two sets of arrows which are easily confusable, see Fig 3. The outer set of arrows moves between posts, while the smaller inner set of arrows (which are right next to and in line with the outer set) move between the individual slides of the slide show. Students often clicked the wrong button and would move to the next student's presentation. This would upset their own train of thought and presentation rhythm. While this provided some comical presentation hiccups, it was generally a negative experience. Near the middle of the semester we held a class discussion and abandoned using Instagram as the presentation tool. However, we decided to continue using the templates to build presentations and 
export that work to a .pdf file for classroom presentation. This helped overcome all three of the issues mentioned above and will be the standard expectation in next year's course.

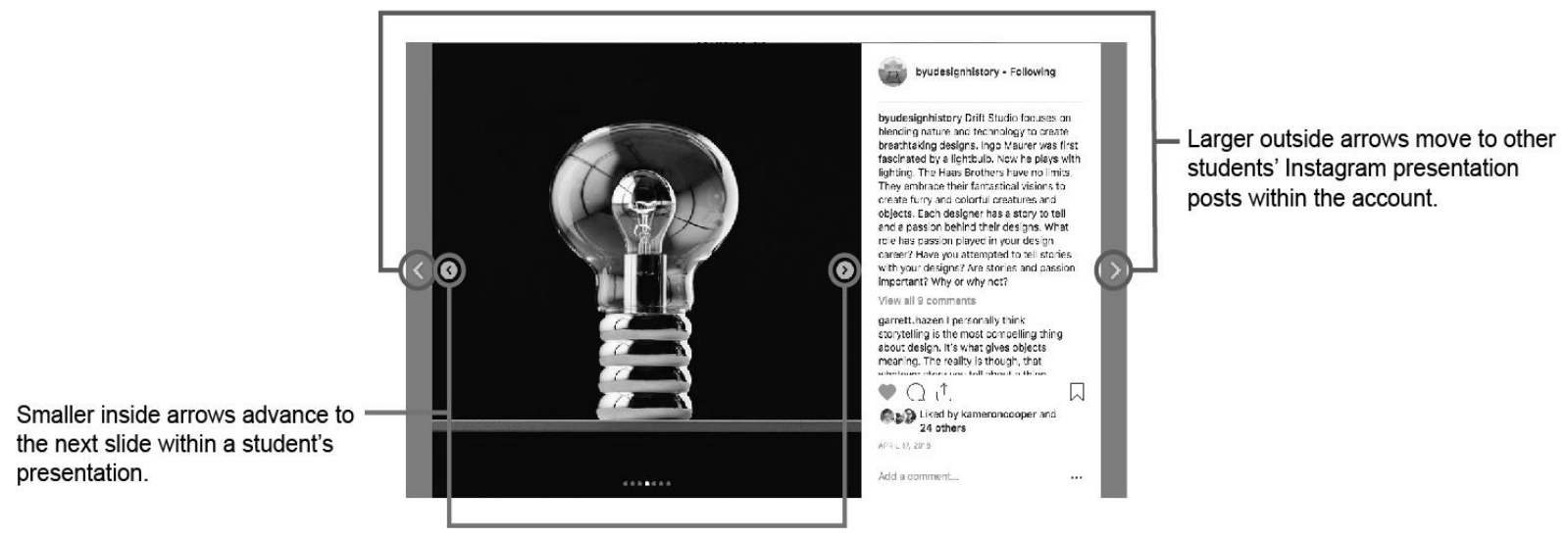

Figure 3. Instagram presentation view highlighting slideshow arrows versus post arrows

\subsection{Presentation Templates}

Requiring the use of templates greatly enhanced the visual cohesiveness on the course postings. As can be seen in Fig. 4, there is consistency, yet variety, over the course's posts. This approach will be continued in future years.

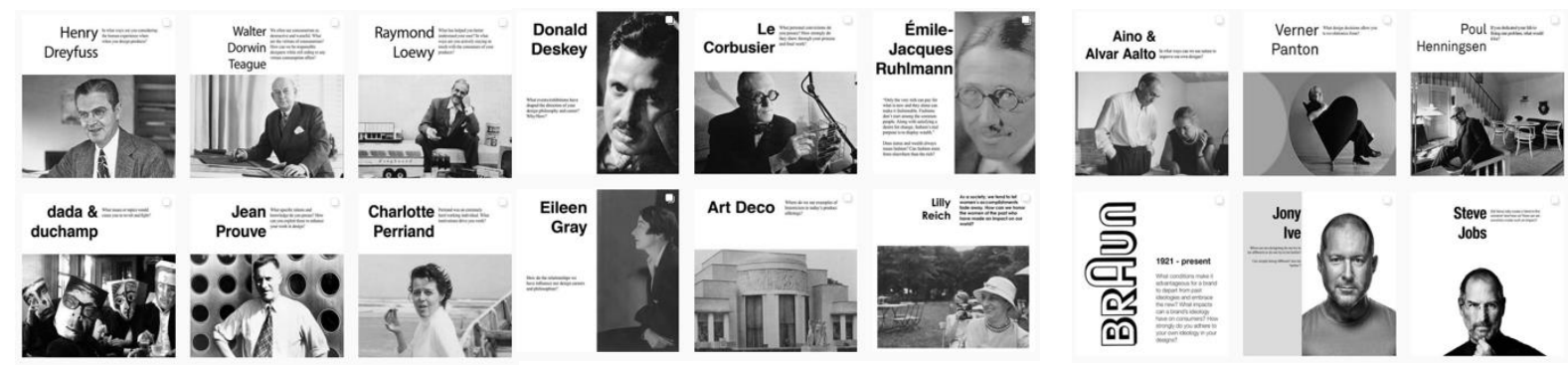

Figure 4. Instagram posts demonstrating cohesive visual identity and searchable names

\subsection{Search Function}

Using a significantly larger font on the first page of the template for the name of the designer greatly enhanced one's ability to find a designer in the multitude of posts, see Fig. 4. Instagram is easily scrollable, and in the mobile format exposes a grid of $3 \times 6$ posts or 18 designers one a single screen. Scrolling through a semester's worth of designers is fairly quick and finding a designer is not nearly as difficult as it was in the previous year's posts. The designers are also generally posted in chronological order which also helps the search.

\subsection{Student Comments}

This year, student comments were still a point of controversy. Each of the three explored proposals resulted in different outcomes. Students liked to make comments as an easy way to gain extra course points but did not naturally engage in ongoing conversations. The instructor often found the posts of poor quality which was an unsatisfactory use of student and instructor time. When posts were required for two weeks, not all the students participated indicating that they needed to go out of their way to make a comment and it was not worth their time. Methods to increase the amount and quality of student comments online is difficult, more on this will be discussed in the survey results below. Next year we will eliminate any expectations about posting comments.

\subsection{Mid-Course Survey}

Responses to the survey questions taught us that $58 \%$ of respondents access their general Instagram account multiple times per day, $32 \%$ per week and $10 \%$ do not use Instagram except for this course. We also learned that $63 \%$ of respondents never comment on Instagram outside of the course, $32 \%$ comment 1-3 times per week and 5\% comment 3-6 times per week. Regarding respondents who looked at the course postings, $10 \%$ of the respondents never look, $80 \%$ view them weekly and $5 \%$ view them daily. 
$73 \%$ of respondents' primary purpose for commenting on Instagram was for course credit, while $27 \%$ felt it enhanced their educational conversation.

When students assessed the perceived value of using Instagram in this course, $16 \%$ felt it was of little value while $84 \%$ felt it was of greater value. Regarding enjoyment, $58 \%$ felt using Instagram was not enjoyable, while $42 \%$ claimed it was enjoyable. Regarding meaningfulness, $75 \%$ felt it was more meaningful while $25 \%$ felt it was less meaningful.

Concerning using templates and PDF files versus PowerPoint, $74 \%$ of respondents felt using templates were helpful, while $26 \%$ felt it was a hindrance and $79 \%$ of respondents would rather view the PDF template presentation while $21 \%$ would rather view an open style PowerPoint presentation.

Thus, we learned that while the majority of students use Instagram in their daily life, few of them make comments on posts. Although the large majority of students view the course posts, most do not comment. Students believe that using Instagram in the course adds value, but they will only make comments for credit. We also learned that while students don't enjoy using Instagram in the course, they find it highly meaningful. Finally, regarding the templates, the students prefer using formatted templates to help them build and view the presentations over an open style of PowerPoint.

As for the open response section, we learned that some respondents felt forcing comments was "fake", while others felt it was a "safe" method to share their ideas with the class. Others recommended the use of \#hashtags and @ presenter on each post which would align more with the natural use of Instagram and would also allow viewers to know which student posted on which designer. Others hoped that more personal experiences about the influence a designer had on the presenter's own work would emerge.

\section{DISCUSSION}

This years' experience exploring Instagram as an educational tool has taught us that posting full presentations using the provided templates was a positive addition to the class. We also learned to avoid using the Instagram website for student presentations and will use .pdf files for future in-classroom presentations. We will continue using the square formatted templates which provide a cohesive visual identity and assistance in searching for a designer. In future courses, discussions are needed with students on how using different fonts and type size confuses the visual cohesiveness of the account, and we will encourage students to adhere to the provided guidelines. We will continue using the same Instagram account, but will place some identification between the different year's postings.

We have found there is limited value in the promise of increasing outside of classroom conversation using Instagram's comments feature. When comments do happen, they should be authentic to the natural curiosities of those participating. However, we also believe that an expansion of the classroom experience occurs through the casual weekly reviews of course content in the student's normal media activities. For next year's course, commenting on posts will not be required and will come with no extra credit incentive. We will continue the one post per designer format with the required addition of including an @ designer and @ presenter to expand the audience. We found that the students value the Instagram account, and that it does enhance their classroom experience as it provides an archive of their presentations. We believe that students will reference their class posts in years to come, and that as they do, it will re-enforce their knowledge and provide evidence of their personal growth as a designer.

\section{REFERENCES}

[1] Brisco R. et al. Recommendations for the Use of Social Networks Sites and Mobile Devices in a Collaborative Engineering Design Project, 2016, 394-399.

[2] Moltenbrey K. Computer Graphics World. Social Situations., 37(4), 2014, 44-50.

[3] Budge K. Visual Inquiry: Learning and Teaching Art. Social Media as Conduit in Art: Understanding Connections to Communities of Practice Through Professional Learning Theory. 4, 2015, 171.

[4] Dominguez-Amarillo S., Fernandez-Aguera J. and Fernandez-Aguera P. Teaching Innovation and the Use of Social Networks in Architecture: Learning Building Services Design for Smart and Energy Efficient Buildings. 12, 2018, 373-374.

[5] Cardall H.Q. and Howell B.F. Using Instagram to Increase Student Engagement with Design History. In Conference on Engineering and Product Design Education, E\&PDE'18, London, September 2018, pp.726-731.

[6] Heer R. Revised Bloom's Taxonomy. Available: http://www.celt.iastate.edu/teaching/effectiveteaching-practices/revised-blooms-taxonomy/ [Accessed on 2019, 22 February]. 